ARTICLE

\title{
The Medium is Global, the Content is not:
}

\section{Translating Commercial Websites}

\author{
YVONNE LEE, University of Warwick
}

\begin{abstract}
Unrestricted by geographic constraints, websites seek to counter linguistic barriers via translation or localisation to reach international web users. Website translation serves as a mediator between users and the reality constructed with multimodal signs in different linguistic and cultural contexts by multinational companies. In comparison with literary translation, website translation is characterised by various unconventional elements, such as the uncertain presence or lack of a definite source text, the choice of multimodal materials for translation, and the representation of meanings in different language versions. Verbal and non-verbal elements, therefore, hold equal significance in the translation process. Considering the complex and interwoven factors in the translation of a website, this paper investigates the non-verbal and verbal signs in commercial websites translation with a corpus of multinational companies (MNCs) operating in Greater China. It argues that translation in commercial websites, contrary to the traditional paradigm with a definitely source-target textual pair, is a fluid concept that involves a 'globally-relevant source text' (Adab, 1998 p.224) that allows space for locally-relevant factors to weigh in to produce content appealing to the target website users.
\end{abstract}

\section{KEYWORDS}

Translation; website; multinational company; social semiotics

\section{Introduction}

Website translation is one type of translation activity nascent in the age of globalisation. Researchers express their views of the new medium with great intensity, seeing technology bringing about drastic changes in the ways in which information is acquired and processed (Horn, 1990, Landow, 1997). The new medium, characterised by attributes such as timeliness, multimodality, hypertext and boundary-transcending capability has redefined the ways in which information is produced, distributed and consumed. The 'space-time compression' 
phenomenon (Harvey, 2000, p. 59) observed in the dematerialisation in trade and commerce also lends itself to the translation scene, where verbal texts in technical documents are produced in different sites in multiple languages for specific target users (Cronin, 2003 p. 43). Nevertheless, this platform is not only a new channel for information exchange but also a powerful instrument in the course of globalisation (Sprung, 2000). The traditional business framework is now overwritten by the World Wide Web where producers are able to reach customers and distributors at the same time, building new revenue streams as well as business models (Chyi and Sylvie, 2001). This feature soon becomes one of the most valuable advantages that both producers and advertisers would like to exploit. Unrestricted by geographic constraints, websites in English seek to counter linguistic barrier via translation, or further localisation, in order to provide specialised contents for International users. Websites that avail themselves of different language options soon become accessible to everyone with access to the internet, regardless of their fluency in English, the lingua franca of World Wide Web. Multinational companies are among the first to recognise this niche and reap the benefit of website translation (Schäler, 2002, Cronin, 2006). Website translation indeed complicates this exploration on two counts. First and foremost, the medium, characterised by multimodal and hypertextual features, challenges and forces an inquiry into the rethinking of the traditional framework of translation analysis. Secondly, if website translation is one type of translation activity nascent in the age of globalisation, to what extent is it (any) different from other translation activities? In the study of literary translation, the analysis focuses on comparison and contrast of the textual pairs in order to investigate the ways in which information travels into target languages. In terms of website translation, the operation itself is characterised by various nature unseen in literary translation, such as the uncertain presence or the lack of a definite source text, the choice of multimodal materials in the translation process, and the representation of meanings in different language versions of a website. The verbal and non-verbal elements in a website, therefore, hold equal significance in the translation process. Considering the complex and interwoven factors involved, we may ask to what extent is this translation practice translation proper, or translation sui generis. This paper attempts to formulate website translation via a close examination of the commercial websites, a significant category of websites and their translation.

\section{Translating Commercial Websites}

The Web is not only a new channel for information exchange but also a powerful instrument for businesses to reach potential customers. With well-maintained multilingual websites, a company can not only project its image across borders but also sell goods online without the material presence of a shop front (Malaval, 2001 p.204). Commercial websites are seen as a 
necessary marketing move to reach out to visible and invisible customers in a real as well as a virtual world. The following discussion of commercial website translation takes into account the interaction and interdependence of three elements, namely the Web, translation and advertising. On at least two counts the translation of commercial websites coincides with advertising translation. First and foremost, advertising and websites are in essence mass communication devices in modern society. Therefore it is crucial to take into account elements of advertising translation in order to investigate website translation. In terms of the commonalities shared by advertisements and websites, Brierley is not the first to claim advertising is one popular and influential mass communication approach, yet he pinpoints some important features of advertisements, that they are loud, ubiquitous and intend to reach as many audiences as possible (1995, p. 123). Guy Cook asserts that advertising is a prominent and significant type of discourse in modern society (1992). Both of these views may be extended to portray the role of websites in our time. Earlier research tends to describe advertising negatively, considering it manipulative and intrusive. Traditionally the study of advertisement has been of great interests to many disciplines. The discourse of advertising has been fully analysed from perspectives of communication studies (Dyer, 1988, Goffman, 1979, Williamson, 1978) and semiotics (Beasley, Danesi and Perron 2000, Cook, 1992, Vestergaard and Schrøder, 1978). However, recent research tends to paint advertising more positively, describing it as creative and lively (see Cook, 1992, Myers, 1999, Goddard, 1998). Furthermore, researchers in both visual communication and translation studies extend this concept and consider local advertising material as translations per se (Kress and van Leewen, 2006, Millán-Varela, 2004), highlighting the significance of non-textual elements in the study of advertising translation whilst establishing their argument on the premise that each advertisement translates the core concept or idea of a product into multimodal texts. Since the corpus under consideration is multimodal in nature, the present research adopts theories of visual design (Kress and Van Leeuwen 2006) so as to investigate how non-verbal elements are transferred into different Chinese websites.

Researchers point out the complexity of advertising, highlighting the fact that advertising involves multiple interactions of different semiotic systems, often with verbal elements sending out tangible information and audio/visual elements enhancing the messages (Scollen and Scollen 2003, Munday 2004). Translation of websites, nonetheless, may find the same pattern in its meaning-making process. A commercial website, whether or not used as an online-sales mechanism, is closely related to advertisements. Like advertisements, content in a commercial website aim to sell. Whether it is service, goods or corporate values, the texts in a commercial website create meaning, images and identities for the products and companies it promotes, as well as prompting consumers' interests. The translations of these texts, therefore, aim to re-create meaning, image and identity of the same product/company across cultures. 
To promote products or corporate image across borders, multinational companies can choose between translation, new campaigns for each locality or an international campaign in English (Munday, 2004 p. 200). Among these three options, translation is cost-effective yet the most likely subject to cultural limitations if the content does not conform to local conventions. However, unlike these options available for advertising and marketing campaigns, a website cannot bypass the pressure of local conventions when translated. The translation process involves numerous factors other than language, such as the understanding of product/corporate image, knowledge of the medium and grasp of target culture. Therefore a substantial understanding of local market is the key to enable successful translation. In short, website translation, like advertising translation, is a task to juggle multiple semiotic systems so as to achieve its objective (Chiaro, 2004, Millán-Varela, 2004). The translation of commercial websites, therefore, aims to identify, translate and carry across the multiple layers of meaning from one language version to another in the hope of achieving the same or similar effect in the target culture. In order to explore the transfer of both verbal and visual elements in commercial website translation, this paper analyses materials from a corpus consisting of English, simplified Chinese and traditional Chinese websites of multinational companies. These websites are compared and analysed at both textual and non-textual levels.

The corpus for this paper includes websites of multinational companies (MNCs) ranging from service industry (DHL, UPS), home furnishing (IKEA), luxury goods (L'Oréal) to FMCG ${ }^{1}$ (Unilever plc and Proctor and Gamble). All of them operate in the Greater China region; their websites include a global portal in English as well as traditional and simplified Chinese websites. Traditional Chinese websites mainly target users in Hong Kong and Taiwan, while Simplified Chinese websites are for potential customers in People's Republic of China (PRC) as well as other Chinese diaspora communities in South East Asia (Singapore and Malaysia, for instance). These MNCs have significant presence in Greater China. They have made their mark on the local markets in Hong Kong and Taiwan with early entries ${ }^{2}$ and have gained significant visibility ever since their recent entries into the Mainland Chinese market. Some of the examples in the current corpus are shown as follows.

\footnotetext{
${ }^{1}$ Fast Moving Consumer Goods: products that are sold at a relatively low cost and are purchased frequently, such as toiletries and household cleaning products

2 L'Oréal, for instance, entered Hong Kong in 1966 and Taiwan in 1980. Unilever Taiwan was established in 1984. Unilever entered China in 1986. P\&G started its Taiwan branch in 1985.
} 


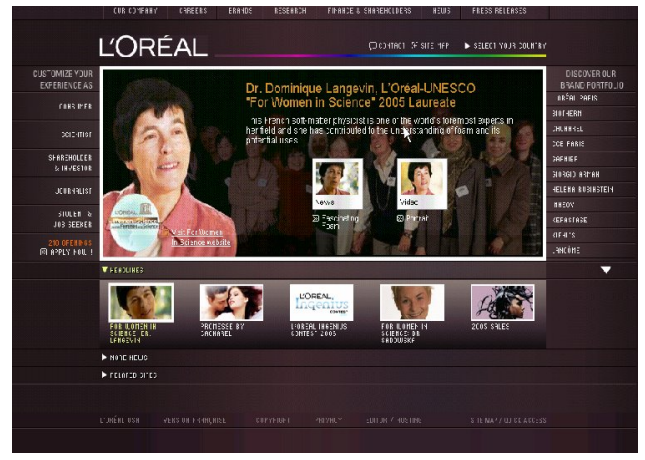

Figure 1-1 L'Oreal Global

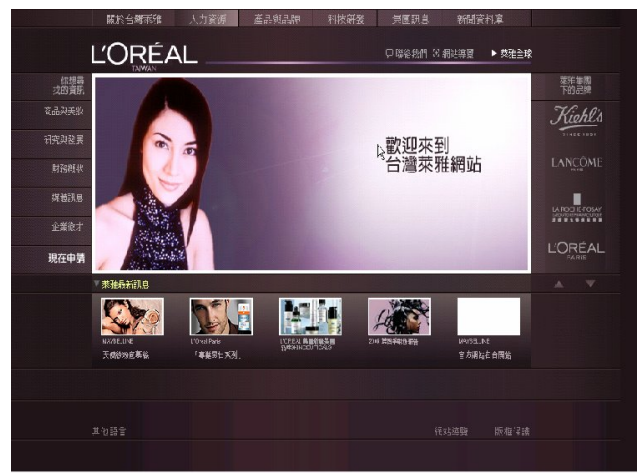

Figure 1-3 L'Oreal Taiwan

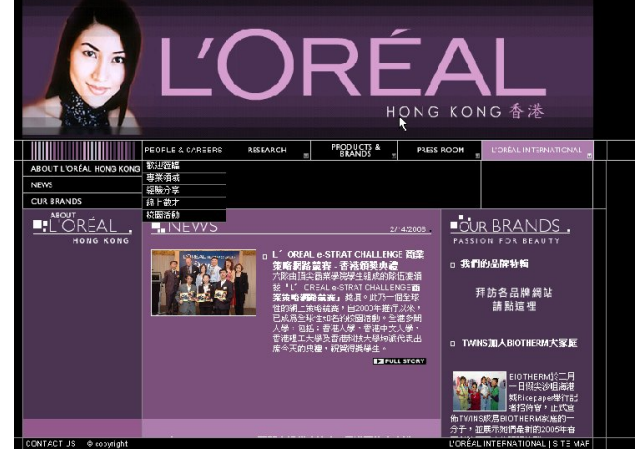

Figure 1-2 L'Oreal Hong Kong

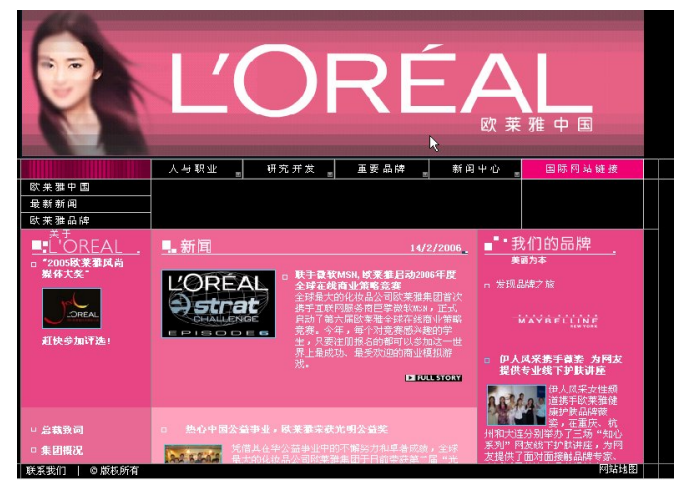

Figure 1-4 L'Oreal China

The figures above are the homepages of L'Oréal websites in English and Chinese languages. These images suggest that there are at least two templates for websites, with figure 1-1 and 1-3 sharing the same layout and the other two another. The figures of different L'Oreal websites offer certain guidance for the discussion. First of all, the verbal elements are undoubtedly an important aspect in the investigation of translational activity. Nonetheless, the layout and other non-verbal elements altogether provide insight into whether or not images/meanings are 'translated'. In figures 1-1 to 1-4 for instance, the spokesperson and colour scheme are very obvious differences. In the global website, the spokesperson in the homepage is a scientist who won a competition sponsored by the company. Clearly the image involved here aims to promote a recent campaign and is thus placed in the eye-catching place, indicating the company's intention to create a positive and involved corporate image. Yet it is important to be aware that this is a temporary promotional event and the image can be replaced anytime after the promotional period. The images of the spokesperson in the Taiwan and Hong Kong websites are the same, featuring an actress based in Hong Kong. The spokesperson in the simplified Chinese website, however, is yet another Chinese actress with whom the local audiences are more familiar. Aside from the image appearing on the homepage, the logo of the company is placed differently in the two templates. The template of the global website presents the logo at the upper-left corner, whereas the Hong Kong 
website template has the logo occupying nearly one-third of the webpage.

In the case of Unilever, the simplified Chinese website is very similar to that of the Global website (please see figure 2-1, 2-2 and 2-3); whereas P\&G Taiwan (traditional Chinese, see figure 3-3), instead of $P \& G$ China (figure 3-2), adopts the global template (figure 3-1) to create the local website.

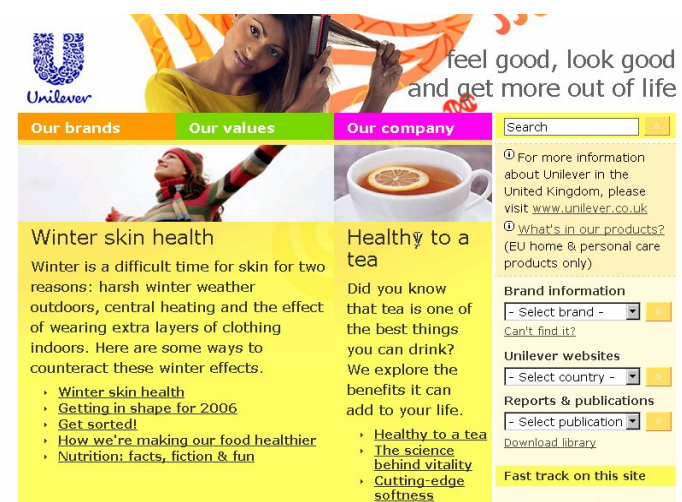

Figure 2-1 Unilever Global

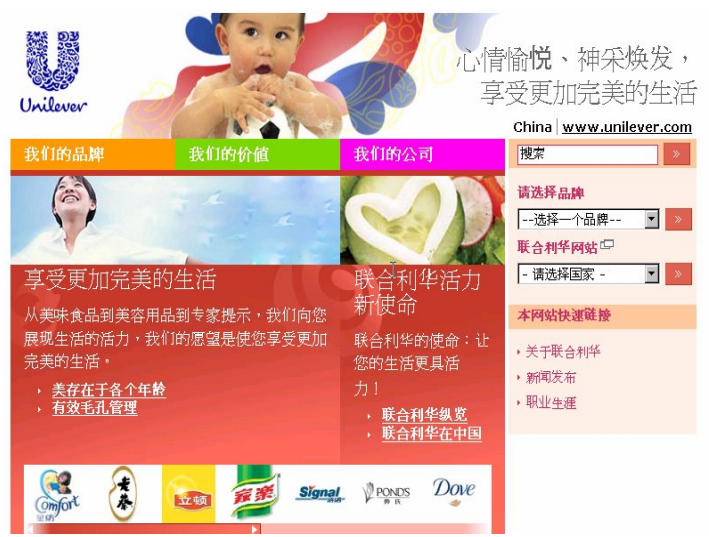

Figure 2-2 Unilever China

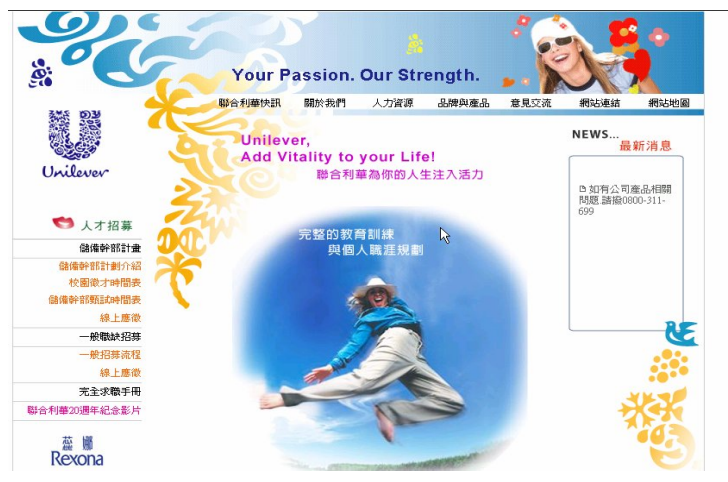

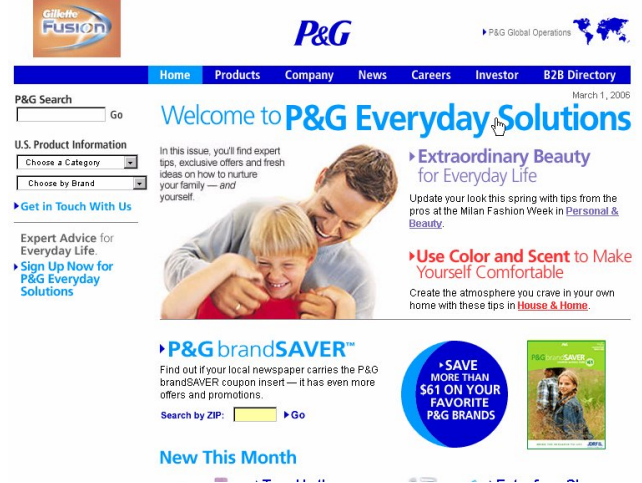

Figure 3-1 P\&G Global

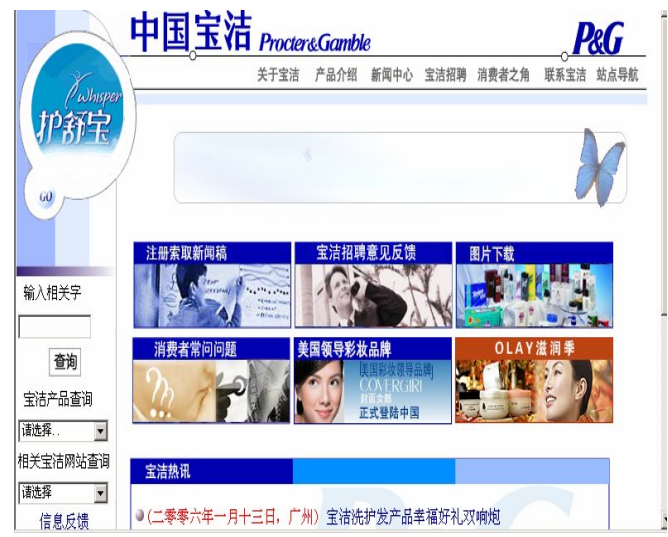

Figure 3-2 P\&G China 


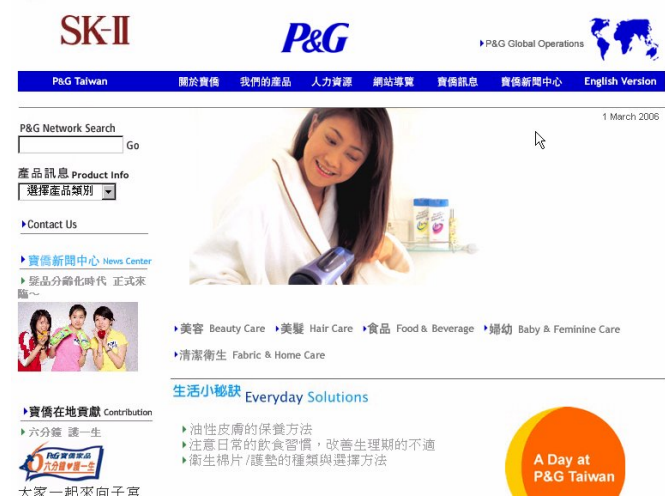

Figure 2-3 Unilever Taiwan
Figure 3-3 P\&G Taiwan

In addition to differences in templates indicated above, the examples also provide information regarding the use of language. In terms of the level of mixed-language, the web pages point out that audience in Hong Kong are the most comfortable with English and Chinese, as the language in websites is rather mixed, juxtaposing both at the same time. Taiwanese website comes next, where product names are mostly left in English. Certain promotional campaigns are likely to preserve English titles as well. The Chinese website, however, is the least likely to mix two languages. The only piece of information in English which appears in the home page is the company name. Although some brand names are preserved in English, the corresponding Chinese translation follows right after. The level of mixed language will be discussed in more detail in the section of verbal elements.

In order to fully analyze these translations of websites, the analysis starts with the discussion of visual elements in the corpus, followed by that of verbal texts; each section is then concluded with the description of strategies adopted in the translational activity.

\section{Versatile Visual Variables}

Ramael proposes that the study of multimedia translation focus on '(translated) texts that do have a verbal constituent, but in a study of which special attention is paid to their multimodal functioning, and to the transformations this might undergo due to the transfer from a source to a target context' (2001, p. 14).. The synergy of multiple semiotic elements, choreographed with written messages, pictorial elements, and audiovisual effects, is exactly what makes websites such a powerful communicative platform. Nevertheless, the synergy of this multimodality introduces a new dimension to translation, as every single local website, regardless of the language it is created in, can be taken as a translation of the global website since the local websites are to appropriately capture essence of the parent websites. With this 
underpinning concept, it is rightly argued that it is necessary to study the movement, or transfer, of the multimodal elements from the global to the local websites.

As evidenced by the majority of multinational commercial websites, the portal or global website often offers the design template for local ones. A universal website template has been embraced by many multinational companies such as DHL, UPS, and L'Oréal, among others. Users find websites with a similar layout easy to navigate irrespective of linguistic differences; moreover, the same design invokes familiarity while contents can be altered for a local touch (Yunker, 2008, p. 280). DHL exemplifies the use of a global template, where every single local website adopts the same layout with its signature red and yellow backdrop. This template not only reinforces brand recognition but also helps users to locate information. However, this 'one-size-fits-all' philosophy does not always apply to all the websites in the corpus. The target for local website and organisational structure together determine whether a global template is suitable for any single local market. For instance, the Unilever Taiwan website is structurally independent from the global and the rest of the country-specific sites. As a stand-alone website in the Greater China region that only caters to the local market, it carries contents that are highly target-oriented, such as graduate recruitments programmes, promotional activities for different brands and the company's history in the local market. Corporate information, such as core values and profile, are not as visible as that in the other websites. This local website has a distinct layout whereby tailored information for the Taiwan market is effectively displayed. This discrepancy is also evident in the Proctor and Gamble Taiwan website. IKEA websites offer further evidence for the difference in template. IKEA apparently offers two design templates for its local websites. Interestingly, within Greater China, Hong Kong and Taiwan websites adopt the same template (the same as the group-corporate website template). This template is also found in certain Asian countries, UAE, Malaysia and Singapore, to name but a few. Yet the majority of other local websites opt for the other template used by the China website. This much more favoured template as seen in the China website is loaded with graphics and animation features, resulting in a much lower downloading speed. Moreover, IKEA made its entry to the Hong Kong market in 1975 and Taiwan in 1994. Both IKEA Hong Kong and Taiwan offer information of local development; in the China website, however, information regarding local involvement and history is nonexistent. The relatively late entry of IKEA into the China market may account for the strategic difference. Since its presence in China is relatively short, the branch in the local market needs to quickly build brand awareness and recognition, making the adoption of the animation-laden template a wise solution since it bears a great resemblance with most of the other international IKEA websites, creating the impression that it is a brand enjoying wide acceptance around the world. This strategy has proved to be successful as its sale figure 
suggests its popularity and surge in sales in China $^{3}$.

The use of images is a semiotic mode that is constantly on display in all types of commercial websites. These websites are highly likely to use portraits to convey messages to web users, regardless of the type of product or service on offer. Among the websites in the corpus, UPS is the only one where portrait is not used. In other words, whether it is service industry (DHL), home furnishing (IKEA), luxury goods (L'Oréal) or FMCG (Unilever and Proctor and Gamble), it is not difficult to find the frequent presence of portraits. It is suggested that images used create interactions between the represented participants (photographed objects) and the interactive participants (website users) (Kress and van Leeuwen, 2003, p. 119). As images are crucial to the presentation of websites as well as advertisements, the interpretation of images, therefore, bears significance to how the product/company/brand is perceived by potential customers. The particular social relation between participant, producer and viewer is projected in any semiotic system, creating an 'interpersonal meta-function' (ibid. 41) that is crucial to the study of website translation. Analysing the transfer of this social relation contributes to the transfer of visual elements in website translation.

Social semiotic theorists tackle the design of an image from various aspects, decoding compositions, frame, perspective and many other elements in images to relate their possible effect on the viewer. For instance, Kress and van Leeuwen contend that the gaze of the participant in an image addresses the viewer directly or indirectly, creating different relations and associations (image act) in communication terms (ibid. 122-158). The interaction between the viewer and the participant of an image is formed at many different levels, including gaze and image act, frame size and social distance, perspective and subject image. The producer of image uses a mixture of all to create images that 'do something to the viewer' (ibid. 122) Taking an example from L'Oréal websites, the gaze of the participants in global and local websites in Chinese all look directly into the viewer eyes, suggesting they demand attention from the viewer. This intense and direct gaze sets out to invite the viewer to form a close social relationship with the participant. In so doing, the participant engages with the persuasion by relating themselves with the viewer. The types of image act created by direct gazes, as seen in L'Oréal websites, form a close connection between the viewers and the participants. With this type of gaze, participants not only 'demand' the viewer's attention and interaction, but ask the viewers to 'desire' what they have, in this case, the attractiveness of the spokesperson using the products. Similar gazes are in fact observed in L'Oréal websites of other countries, including its websites in the US and UK as well as all three in Greater China. Although the participants differ according to the different contexts, usually featuring iconic actresses/models highly relevant to local markets, the type of direct

${ }^{3}$ China is the largest country of purchase www.ikea.com/ms/en GB/about ikea/facts figures/figures.html 
gaze remains the same in different local websites. This gaze, in turn, is translated via different actresses/models that are well-received by the local market looking directly at the website users.

To sum up, the same message is clearly carried across borders into websites in different localities. Using the same gaze, the brand is inviting viewer to pay attention to this brand and enticing them to explore the products they promote. Using different participants, the websites garner familiarity and recognition from local users. These portraits, in which the similarly intense gaze strongly engages the web surfers, should be taken as fully translated into websites of different localities despite the differing choice of participants.

The analyses of visual elements indicate that non-verbal representations are used in a variety of ways to facilitate the meaning-making process. The analyses also demonstrate that in spite of certain individual cases ${ }^{4}$, most of the websites 'translate' the visual elements with a local twist by using high-profile participants or people of the same race in the portrait. The analyses also suggest that among the multinationals, luxury goods providers are more likely to rely on non-verbal presentations, echoing Nord's perspective: 'It may happen that the non-verbal elements convey a piece of information that is even more relevant to the reader than the message transmitted by the text' (1991 p. 109).

\section{The Intangible Texts: Linguistic Transfers}

Written texts are one type of text that is almost always compulsory in any website, regardless of how salient other visual components may be. For commercial websites, written texts are the apparatus to deliver desired results or fortify existing ideas of a brand, a product, or a type of service. However, not all written texts bear the same significance in a website. As a general rule a piece of written information is meant to send out a certain message to the reader, be it one more click on the mouse to 'find out more', or a click away to navigate to another relevant website that the message-sender intends to draw attention to. In other words, in order to gain some control over the website users reading sequence, written messages are required to be carefully tended and produced. In commercial websites, written texts can be either functional (such as 'our product' on the navigation bar) or promotional (main body of texts delivering product or brand information). The former, due to its functional feature, is mostly translated literally and directly with little alteration; the latter, however, may be rewritten to a greater or lesser extent. The main reason underlining this discrepancy in translation is the

\footnotetext{
${ }^{4}$ As suggested earlier in this section, among the MNCs in the corpus, UPS is the only one where portrait is not used in its websites.
} 
purpose for which the piece of text is intended. For a new product modified for one particular international market, its specification and product description may be re-written to meet the needs of its local customers. By contrast, information regarding the profile of a multinational may be translated as closely as possible so as to deliver a consistent corporate image. This type of information, including the core value, brand names, and corporate history facilitate the recognition of a company as well as its products and services (Cook, 1992). According to Vestergaard and Schrøder, description of corporate history is 'the so-called prestige or good-will advertising', where the image, instead of the product, is advertised (1985, p.1). This type of promotional text aims to create a positive corporate profile, targeting 'long-term goodwill with the public rather than at an immediate increase of sales' (ibid). Therefore, corporate history, mission statements and values comprise of a crucial and consistent element throughout global and local websites of a multinational company. This type of text, nevertheless, can usually find its counterpart in a local website, however adapted or abridged. Applying Roman Jakobson's theory of intersemiotic translation, the corporate profile is a manifestation of intersemiotic translation whereby a company's corporate values, concepts, philosophy and history are 'translated' into words (1959). These texts are crucial to the image of the corporation around the world; they are obliged to be consistent since they may be under scrutiny by not only web users but shareholders across borders. However distant and different a target culture may be, the corporate information must deliver the same effect and message in the local websites. Since corporate information is the only type of written text with a more liable source and target in a commercial website, a selection from each website in the corpus is analysed to outline the translation of verbal elements.

However consistent or coherent it intends to be, textual analysis of all corporate profiles reveals unquestionable discrepancies in the translation across regions within Greater China. Moreover, not every single piece of information shaping the corporate image will be translated into Chinese. In each Chinese text it is possible to identify traces of 'translation' when compared with the English corporate information; however, it is undeniable that the reasons for, and methods of the selection of material largely depends on the relevance it has in relation to the locality and the organisational structure between the parent company website and a particular local website. The most striking discrepancy comes to light comparing the translation of corporate information and other written passages in the same website. While promotional texts of a certain product, targeting local markets, may be subject to deliberate alterations, such as rewriting and adaptation so as to cater to local tastes, often sounding approachable and uplifting, the corporate information is delivered in quite a different and more reserved tone, marking a clear divide in the written texts within any one single Chinese website in the corpus. The situation is exemplified by Proctor and Gamble websites. The corporate profile in the Proctor and Gamble global website contains 
information regarding its purpose, values and principles. In the local website for PRC, all the information is selected and closely translated in a formal manner with long and archaic sentences that read as if they are pledges given by the staff. However, this businesslike tone does not dominate other texts in the China website. In fact, this China website offers a mixture of information that may be generated locally or derived from a global source. The promotional texts regarding product information or activities almost always lay out a lively and cheerful tone. For instance, the product information for Pringles potato chips in Proctor and Gamble Global website is a concise passage of 48 words where users are encouraged to click on the hyperlink on the same page to explore Pringles' own website. However, the equivalent page in Proctor and Gamble PRC website offers a passage with two paragraphs at a word count of 458 , where the late entry of the brand, its product feature and appeal are highlighted. Moreover, this passage is marked by the marketing slogan of Pringle's chips especially for the Mainland Chinese market; this piece of information also marks another clear divide with its counterpart in the Global website. Its translation back into English reads '...share Pringles chips is to share happiness, this is probably the exact reason why everybody loves Pringles chips!' In so doing, the texts offers not only factual information but advertising rhetoric and expressions in order to persuade. The hybrid of messages marks a vivid disruption in the coherence of texts in the China website. The China website not only offers information for local consumers but information about the corporation to users with an interest of the company. Since this website targets local customers and caters to inquisitive international users, locally-relevant information clearly relates to Chinese users whereas company information complies with its corporate regulations and conventions. The result is a website speaking both formal and colloquial Chinese.

By contrast, the Taiwan website is rather selective in its choice of translation. Among the messages in the corporate profile webpage, only information about 'our purpose' is chosen from the global website. However, this passage just remotely responds to the English counterpart. To say it fully translates the 'our purpose' section might not be appropriate, as this passage also contains and integrates information from other sources, which indicates a high level of adaptation undertaken to produce the texts for the Taiwanese market. The same adapting and rewriting style is repeatedly applied to other parts of the website, creating a montage of corporate profile in translation. Since the Taiwan website targets mostly local users instead of international surfers, the website itself places more emphasis on the range of products available for the local market. As a whole, any information regarding corporate value and the company ranks secondary in terms of relevance to the locality. As a result, all information about the organization tends to be selectively chosen and rewritten for the local market. The space available is left for locally generated contents. 
As mentioned above, Proctor and Gamble and Unilever are likely to adopt similar strategies to set up local websites. Although both companies have largely restructured the markets in Great China and integrate Hong Kong into the Chinese market, they do recognise the heterogeneity of the Taiwan locality and the fact that there is a longer market presence in the traditional Chinese market. This nonetheless indicates the multinational companies' awareness of the difference in their potential customers and the efforts they put in maintaining different websites. In her comparative study of print and web advertising, Chiaro argues that multinationals are more aware of cultural nuances and have more resources to modify the translated texts for different markets, which holds true for these two retail giants (2004, p 325-326).

Text analyses reveal that the translation of corporate information is approached differently. As evidenced by Unilever and Proctor and Gamble, FMCGs needs to strongly promote the core value of its producers (de Mooji, 1998) and thus need to translate and adapt the texts so as to produce a localised key concept encapsulated in the website. Luxury, or non-essential products and services, on the contrary, might adopt a more extreme approach, either strongly appealing to the international market, or adamantly guarding the brand image. The example from L'Oréal underpins this clear divide. Adab observes that in order to successfully persuade consumers into purchasing goods, the advertisements often needs to extend written texts (2002, p. 142). This holds true for FMCGs, yet does not apply to luxury goods, whose websites usually prefers to accentuate its non-verbal semiotic modes to speak for the products.

Reuse of written texts in websites is not uncommon. Commercial websites operating in English often reuse texts for multiple locations as content synergy for cost-saving reasons; so do Francophone countries using French and Russian for former-Soviet Union Countries. The same phenomenon is observed by MNCs (Unilever plc and $P \& G$ ) operating in central and south America, where a specific Spanish version is created for countries such as Peru and Venezuela. By the same token, a Maghreb website is created to cater to Northern African francophone countries. However, in Greater China the reused text is the less circulated Traditional Chinese evidenced by Hong Kong and Taiwan websites. For instance, the IKEA websites in these two locations have corporate information that reads almost identically where back translation fails to demonstrate the nuances. The same case is found with UPS websites. While both offer simplified and traditional Chinese information, the former targets the vast majority of users in China; the latter, nonetheless, finds its niche for users in Hong Kong and Taiwan, where traditional Chinese characters dominate the writing convention. McDonough contends that when the linguistic and cultural differences between two local markets are minimal, translations in websites may not merit changes or adaptations for each locality (2004, p. 99-100), which justifies the re-use of translated texts in the Hong Kong and 
Taiwan websites, where both localities share similar linguistic convention and have a longer history of foreign traders' presence in the local markets.

As mentioned above, commercial websites may demonstrate very different attitudes towards the translations of texts owing to the intended function (factual or promotional) of each piece of information. Since brand names facilitate recognitions of the product or service, the translation of brand names and its presentation offer some insight as to the way in which local customers identify the brand. The translation of brand or product names has been well-documented in the field of advertising translation (Motished 2003, Philippson 2003). The translation of brand names, in addition to its multi-faceted difficulties linguistically and culturally, offers an interesting site in which the source and the target language engage in another tug of war. In the commercial websites, the Chinese translations of brand names may not stand alone in the logo despite all product names being duly translated for the target market. Take the instance of the FMCGs in Unilever websites. In the Taiwan website, only three out of ten logos are displayed in their translated Chinese brand names; one logo has both its English name and its Chinese translation. The rest of the six brand names all remain in English in its logo. Among the 15 brands available in China, only three are displayed without Chinese translations. In other words, English is equally or more visible than Chinese in more than half of the logos in these two Chinese websites.

Mixed language is one commonality shared by FMCG and luxury products. The L'Oréal Hong Kong website demonstrates a high level of mixed language use where it occurs not only in the presentation of logo and brand names, as all brand names in Hong Kong website are not translated, but also with campaigns and corporate information. The Hong Kong website is also the only one in Greater China that provides a direct link to all-English information, where the user accesses features about skincare information and procedure. This in fact suggests that users of the Hong Kong website are expected to read bilingually. The L'Oréal Taiwan website adopts a more neutralised approach. It is likely to find brand names remaining in Chinese, although they always accompany the original brand names. In fact the customers might not even be aware of the translated names since the brand names in English are much more marketed and promoted. Brand names preserved in its source language deliver a sense of tradition and its foreign origin among the potential or existing customers, effectively creating the image which the non-essential product aims to deliver. By contrast, the China website is the least likely to display texts in languages other than Chinese. The brand names are dutifully rendered into Chinese and accompanied by their original, implying that the mainland Chinese customers are much more inclined to recognise and identify with a certain luxury product in Chinese. In fact, looking into the array of products of the multinational companies in the corpus, the brand names are the most likely to be transliterated/translated for the mainland Chinese users, reflecting the habit of using purely 
local language instead of mixed-language.

\section{Conclusion}

In a study of the marketing strategies of US online newspaper websites, the researchers aptly describe the online versions of news papers that 'the medium is global, the content is not' (Chyi and Sylvie, 2001, p. 231). I would like to suggest that the same phenomenon fits well with the localised commercial websites. In the age of globalization, when 'no translation, no product' (Topping, 2000, p. 111) becomes not only a catchphrase but tacit knowledge of multinational companies, the translation of websites highlights the significance of translation in the multinationals' attempt to break geographical restrains. FMCGs and Luxury goods place a different focus on the use of semiotic modes; the former see verbal descriptions crucial while the latter tend to 'let the image/picture speak'. In terms of written texts, the text analyses aptly reflect the much-hyped keyword 'glocalization'. By being 'glocalized', the local websites in Chinese adopt a hybrid translation strategy to cater to culturally-specific needs in the three localities. In this translation practice, there is a 'globally-relevant $\mathrm{ST}^{, 5}$ (Adab, 1998, p. 224) that mainly consists of conceptual ideas which will be translated into different local websites. The flexibility of the conceptual source, although a methodologically complicated subject to tackle, is the very reason behind the fluidity and versatility of commercial websites and their local counterparts. Messages which will have similar impact across cultures are carefully selected and repackaged in multimodal representations in local websites. Despite the necessity to resort to text analysis to study written texts, the above discussion demonstrates that it is the ideas, instead of tangible written texts, that travel across borders into websites that speak different languages.

\section{References}

Adab, B. (1998) 'Towards a More Systematic Approach to the Translation of Advertising Texts' in Beeby, A., Esinger D., and Presas M. (eds.) Investigating Translation Amsterdam: John Benjamins 223-34

-------. (2002) 'The Translation of Advertising: A Framework for Evaluation' Babel 47 (2): $133-57$

Beasley, R., Danesi M. and Perron P. (2000) Signs for Sale: an outline of Semiotic Analysis

\footnotetext{
${ }^{5}$ ST, source text, an abbreviation commonly used in Translation studies.
} 
for Advertisers \& Marketers New York: Legas

Brierley, S. (1995) The Advertising Handbook London: Routledge

Brooks, D. (2000) 'What Price Globalization? Managing Costs at Microsoft' in Sprung, R. (ed.) Translating into Success: Cutting Edge Strategies for Going Multilingual in a Global Age Amsterdam: John Benjamins

Chiaro, D. (2004) 'Translational and Marketing Communication: A Comparison of Print and Web Advertising of Italian Agro-Food Products' The Translator 10 (2) 313-328

Chyi, H. and Sylvie G. (2001) 'The Medium is Global, the Content is Not: The Role of Geography in Online Newspaper Market' Journal of Media Economics 14 (4) 231-248

Cook, G. (1992) The Discourse of Advertising London: Routledge

Cronin, M. (2003) Translation and Globalisation London: Routledge

-------. (2006) Translation and Identity London: Routledge

de Mooji, M. (2005) Global Marketing and Advertising: Understanding Cultural Paradoxes London: Sage

Dyer, G. (1998) Advertising as Communication London: Routledge

Esselink, B. (1998) A Practical Guide to Software Localization Amsterdam: John Benjamins

Goddard, A. (1998) The Language of Advertising London: Routledge

Goffman, E. (1979) Gender Advertisements London: Macmillan

Guidère, M. (2001) 'Translation Practices in International Advertising.' Translation Journal 5 (1). Available from http://accurapid.com/journal/15advert.html [accessed 12 March 2006]

Halliday, M. (1985) An Introduction to Functional Grammar London: Edward Arnold

Harvey, D. (2000) Space of Hope Edinburgh: Edinburgh University Press 
Horn, R. (1990) Mapping Hypertext: The Analysis, Organization, and Display of Knowledge for the Next Generation of On-Line Text and Graphics Arlington: Lexington Institute

Hung, E. and Wakabayashi J. (eds.) (2005) Asian Translation Traditions Manchester: St. Jerome

Kress, G. and van Leeuwen T. (2006) Reading Images: The Grammar of Visual Design London: Routledge

Landow, G. P. Hypertext 2.0: the Convergence of Contemporary Critical Theory and Technology Baltimore: John Hopkins University Press, 1997

Malaval, P. (2001) Strategy and Management of Industrial Brands: Business to Business Products and Services Boston: Kluwer Academic Publishers

McDonough, J. (2006) 'Hiding Difference: On the Localization of Websites' The Translator 12 (1) $85-103$

Millán-Varela, C. (2004) 'Exploring Advertising in a Global Context: Food for Thought' The Translator 10 (2) 245-267

Munday, J. (2004) 'Advertising: Some Challenges to Translation Theory.' The Translator 10 (2) 199-219

Myers, G. (1999) Ad Worlds: Brands, Media, Audiences London: Arnold

Nord, C. (1991) Text Analysis in Translation Amsterdam: Rodopi

O'Hagan, M. and Ashworth D. (2002) Translation-mediated Communication in a Digital World: Facing the challenges of globalization and localization Clevedon: Multilingual Matters

Ramael, A. (2001) 'Some Thoughts on the Study of Multimodal and Multimedia Translation' in Gambier Y. and Gottlieb H. (eds.) Multimedia Translation Amsterdam: John Benjamins

Schäler, R. (2002) ‘The Cultural Dimension in Software Localisation' Localisation Ireland 1(2) 21-23 
Scollen, R and Scollen S. (2003) Discourse in Place: Language in the Material World London: Routledge

Sprung, R. (ed.) (2000) Translating into Success: Cutting Edge Strategies for Going Multilingual in a Global Age Amsterdam: John Benjamins

Topping, S. (2000) 'Shortening the Translation Cycle at Eastman Kodak', in Sprung, R. (ed.) Translating into Success: Cutting Edge Strategies for Going Multilingual in a Global Age Amsterdam: John Benjamins 111-26

van Leeuwen, K. (2003) 'A Multimodal Perspective on Composition' in Ensink T. and Sauer C. (eds.) Framing and Perspectivising in Discourse Amsterdam: John Benjamins 23-62

Vestergaard, T. and Schrøder K. (1985) The Language of Advertising Oxford: Blackwell Wells, W., Burnett J. and Moriarty S. (1998) Advertising: Principles and Practice. London: Prentice-Hall International

Williamson, J. (1978) Decoding Advertisements: Ideology and Meaning in Advertising London: Marion Boyars

Yunker, J. (2003) Beyond Borders: Web Globalization Strategies Indianapolis: New Riders

\section{Websites consulted}

www.loreal.com/_en/_ww/index.aspx

$\underline{\text { www.lorealparis.co.uk/Celebrities/index.asp?testCookie=true }}$

www.lorealparisusa.com/frames.asp\#haircolor/index.asp

www.lorealv2.com.tw/ zh/ tw/

www.pg.com/en_US/index.jhtml;jsessionid=3QH1C0NZ0YHVFQFIAJ4S0JGAVABHOLM

www.pgtaiwan.com.tw/pg/site/index.php

www.pg.com.cn/

www.unilever.com/

www.unilever.com.cn/

www.unilever.com.tw/

www.ups.com/

www.dhl.com/splash.html

www.ikea.com/ 
